\title{
REVIEWING THE 2016 KUMAMOTO EARTHQUAKE DAMAGE IN MASHIKI TOWN AREA BY USING MICROTREMOR MEASUREMENTS
}

\author{
TARA NIDHI LOHANI ${ }^{1}$, TAKASHI NAGAO $^{1} \&$ YASUHIRO FUKUSHIMA $^{2}$ \\ ${ }^{1}$ Research Centre for Urban Security and Safety, Kobe University, Japan. \\ ${ }^{2}$ Eight-Japan Engineering Consultants Inc. (EJEC), Japan.
}

\begin{abstract}
The 2016 Kumamoto Earthquake has caused vast building damages and human losses, although Japan is one of the world's well-prepared countries against earthquake disaster. The accelerometers set in Mashiki town area of Kumamoto prefecture rolled to the full scale measuring the seismic intensity as 7 in JMA scale of 7. In addition to such large shaking, there are opinions about the existence of three parallel fault lines beneath the town and the area lying on very soft volcanic soils regarding the vast damage of this particular area. In order to investigate the soil behaviour of this area, microtremor array studies were conducted starting from April 2016 to September 2016. Phase velocity obtained by spatial autocorrelation method was cross-checked with the borehole data available and was also found to be correlating well. Besides, the shear wave velocity distribution in the field was also consistent with the extent of damage observed after the earthquake.
\end{abstract}

Keywords: Earthquake, Kumamoto, Mashiki, microtremor, shear wave velocity.

\section{INTRODUCTION}

On April 16, 2016, Kumamoto Prefecture in west Japan was hit by a big earthquake of M7.3 and, as per Japan Meteorological Agency, JMA, Mashiki town and surrounding areas in central Kumamoto were shaken by intensity 7 in JMA seismic intensity scale. The same level of shaking was generated in Mashiki town by the foreshock 2 days before. The Mashiki town area was worst hit with large building damages and human losses. The Ministry of Land, Infrastructure and Transport (MLIT) Japan report [1] shows that three parallel fault rupture lines run in parallel beneath this small town. The right strike slip fault movement of Hinagu-Futagawa fault system that triggered the tremor, also lies in a very close proximity.

Earthquakes over magnitude 4.5 within the year 2016 from April 14th are plotted in Fig. 1. The NE-SW trend of epicentres extending from Kumamoto City to Oita City area could be visualized. Besides, the geology of the area shows that it is covered by very soft volcanic soils. In other words, large shakings, underlying fault lines and very soft layer of underlying volcanic soil have invited such vast disaster in the area. Photograph shown in Fig. 1 was taken in the field where almost $2 \mathrm{~m}$ lateral displacement was observed.

\section{MICROTREMOR FIELD SURVEY}

In order to study the underground behaviour, microtremor study was done in the field [2]. Total of four visits were done in the Mashiki town area from April to September 2016 in order to assess the damage situation and conduct field measurements. The devices used in measurement had a very sensitive accelerometer of natural period $1 \mathrm{~s}$.

In this research, measurements taken in July (prefix JA, JS) and September (prefix SS) 2016 (Fig. 2) are discussed. The July array measurements were done in a detailed way, with 


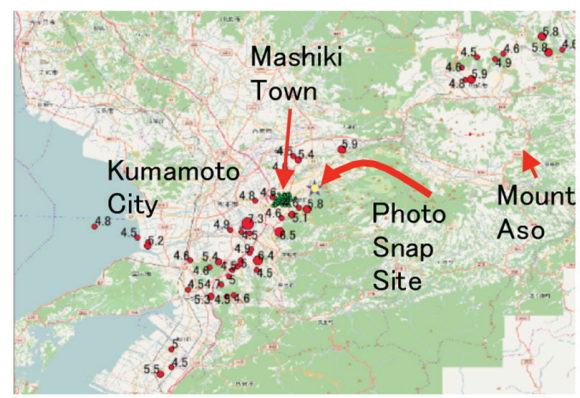

(a)

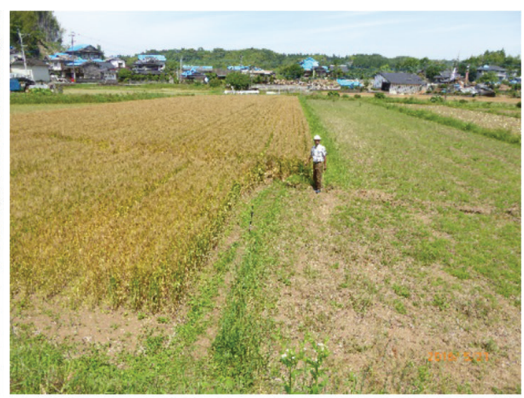

(b)

Figure 1: a) Earthquake shakings over magnitude 5.0 within the year 2016 starting April 14th, and b) Photo shows a ground shift of about $2 \mathrm{~m}$ along the fault.

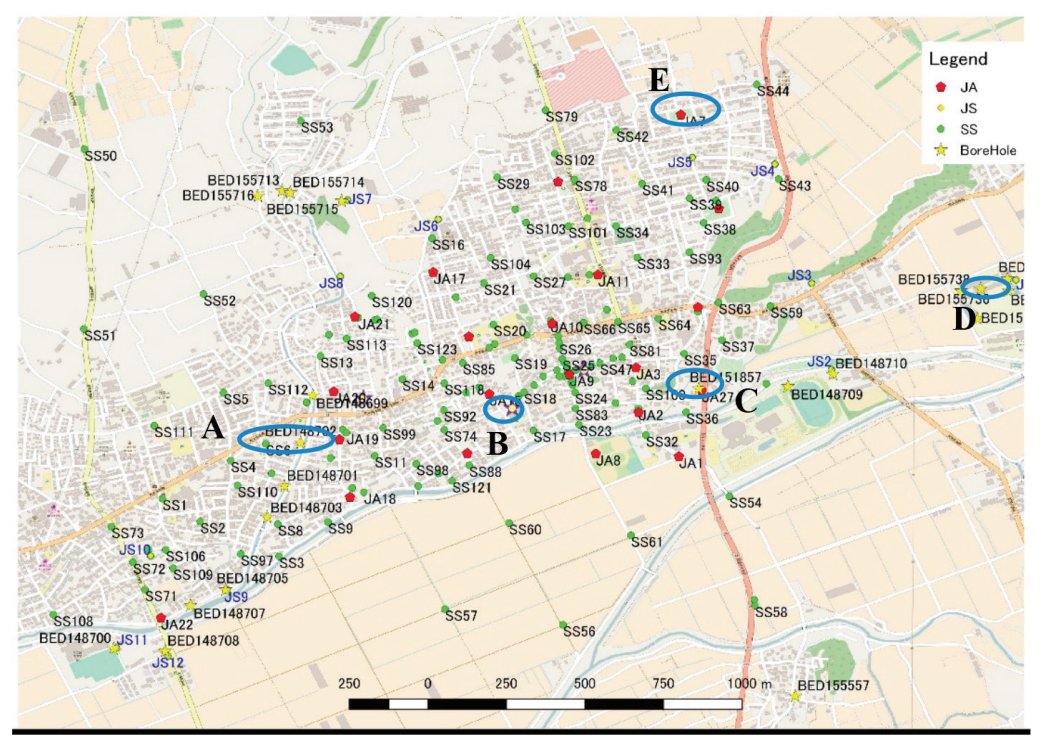

Figure 2: Microtremor measurements taken in July (JS, JA) and September (SS), in Mashiki Town, Kumamoto (A: Array, S: Single Device, measurement).

three devices set in a radial direction and one, at the centre (Fig. 3). The radial distance was varied from 4 to $32 \mathrm{~m}$ in general. The recording time was $6,8,11$ and $11 \mathrm{~min}$ respectively. In addition, some recordings continued up to $20 \mathrm{~min}$. Measuring devices were synchronized on each day by using GPS signal before performing the field measurement.

The recorded binary files consisted of the data in east-west (EW), north-south (NS) and UD (up-down) directions written at $100 \mathrm{~Hz}$ sampling frequency. The H/V spectra of the wave records were calculated in order to get an information of the in situ natural frequency [3]. Smoothing of both horizontal and vertical component of the recorded microtremor traces was done by using a Parzen window with a bandwidth of $0.2 \mathrm{~Hz}$. By considering an influence of long period components negligible, only $40.96 \mathrm{~s}$ interval of the observed data at three minimum disturbed sections were selected and averaged to obtain the average $\mathrm{H} / \mathrm{V}$ spectra. The horizontal 


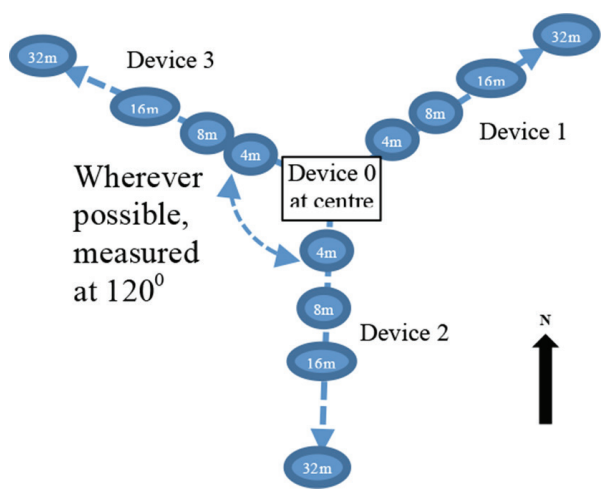

Figure 3: Array measurements done in the field with four devices, one at the centre and three other devices in radial direction.

component was obtained from the square root of the mean of the square of two orthogonal components. Figure 4 shows typical H/V plots prepared for JA7, JA9 and JA20 stations that are not so far from the locations E, B and A, in Fig. 2. The natural period of around $0.8 \mathrm{~s}$ could be noticed for JA9 station, where the housing damage was also found heavier during site visits.

The peak frequency (PF) distribution map (Fig. 5) was prepared by getting the peak position of $\mathrm{H} / \mathrm{V}$ plots and plotting them by using inverse distance weighting method. Considering the possible non-linearity of underlying soil that might alter the natural period of the site along with an elapse period after the earthquake, only the data taken in July and September were plotted. The general trend is higher PF values (shorter natural period) in N-E region and lower PF values (longer natural period) in S-W region. Specifically, very long natural period along the Prefectural highway running EW at the centre of the map and southward could be noticed.

The phase velocity profile was obtained by considering spatial autocorrelation method [4] at all stations where array measurements were done (ref JA prefix in Fig. 5). The analysis was done by including UD component data and applying two different combinations of points in the analysis; i) between the stations at the centre and those set at the specified radial distance along the circumference, and ii) between the stations along the circumference. The average phase velocity plot was then obtained by combining all the plots for various distances together and the average trend was noted manually on this line (plotted as 'Observed in Fig. 6). Haskell

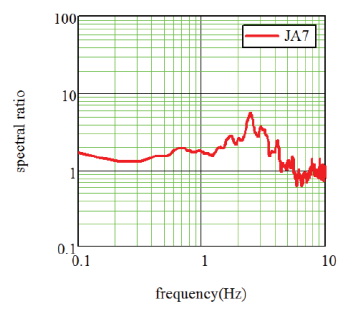

(a)

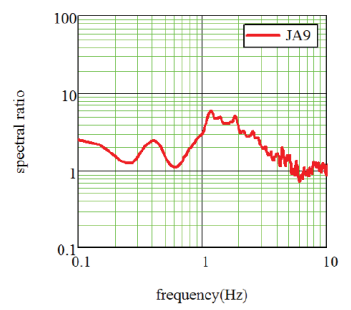

(b)

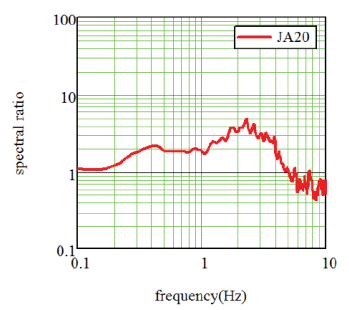

(c)

Figure 4: H/V plots for array stations; a) JA7, b) JA9, and c) JA20. 


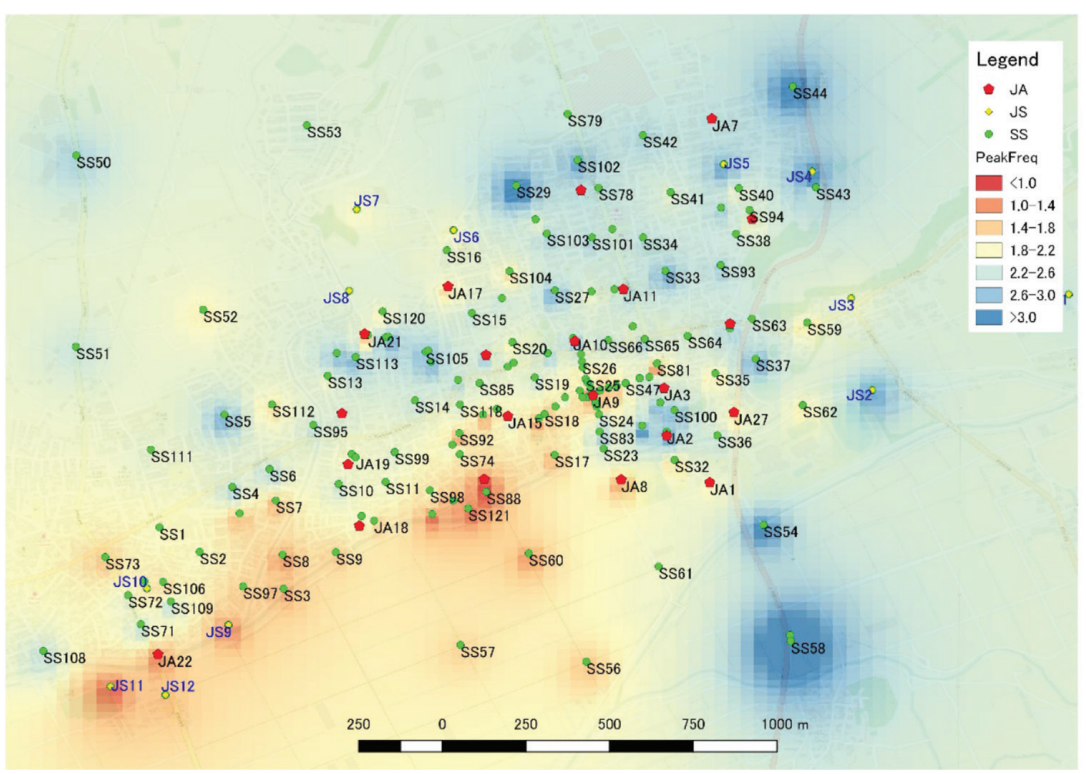

Figure 5: Peak frequency distribution map of Mashiki town area observed from H/V spectra of the data recorded in July and September 2016.

[5] method was applied to obtain the velocity profile [6] at each station. While doing this, underground soil conditions and depths were varied by observing the nearby boreholes, if exist, and phase velocity curve (plotted as 'Calculated' in Fig. 6) was obtained. For example, the JA7 point, which is very close to KMMH16, a KiK-net station [7] and borehole data is also available [8], was a very good reference to start the calculation. The phase velocity curves for three stations, JA7, JA9 and JA20 are shown in Fig. 6. Based on the velocity profile obtained in this way, an average velocity for the top $10 \mathrm{~m}, 15 \mathrm{~m}, 20 \mathrm{~m}, 25 \mathrm{~m}$ and $30 \mathrm{~m}$ was calculated. While such data are available only at array measurement stations, the distribution plot of whole area (Fig. 7) was prepared by using inverse distance weighting method, similar to that used in preparing Fig. 5. This plot will be referred again later in the following

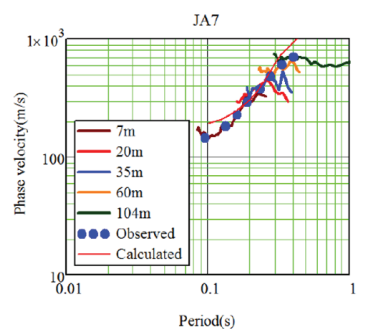

(a)

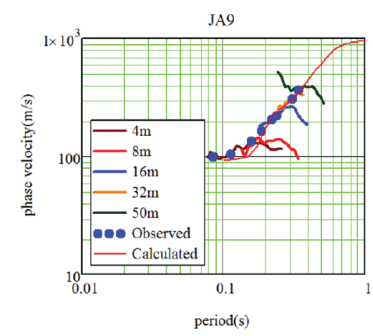

(b)

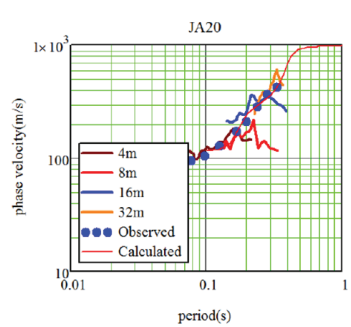

(c)

Figure 6: Calculated and observed phase velocity plotted together with spectral plots for various distances at locations; a) JA7, b) JA9, and c) JA20, respectively. 


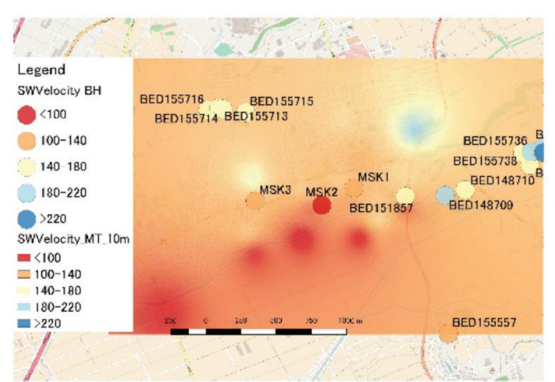

(a)

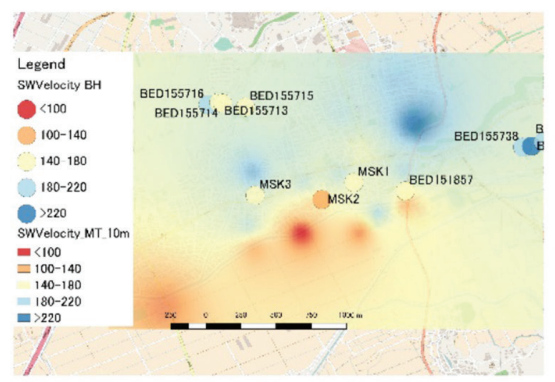

(c)

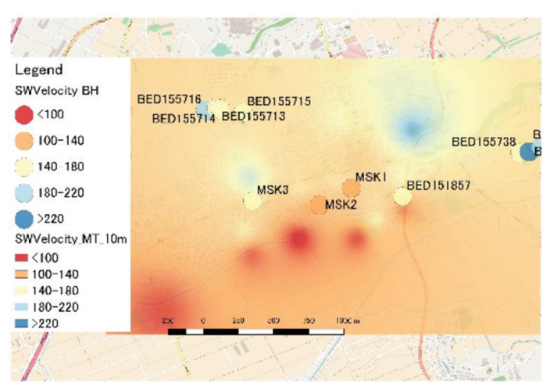

(b)

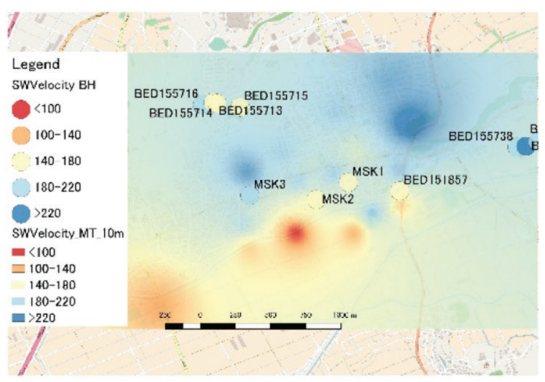

(d)

Figure 7: Calculated shear wave velocity from the borehole soil profiles drawn over the average shear wave velocity distribution map obtained by for the top; (a) $10 \mathrm{~m}$, (b) $15 \mathrm{~m}$, (c) $20 \mathrm{~m}$ and (d) $25 \mathrm{~m}$.

paragraphs with additional data. There is an obvious and clear trend of increase in velocity with depth and localized variation of underground soil could be noticed.

\section{INTERPRETATION OF BOREHOLE DATA}

Boring data from Kumamoto Earthquake Reconstruction Support [9] borehole map was used to obtain the soil profile data at various borehole locations. Calculation of shear wave velocity was done from the given SPT data at various depths by using the relation proposed by Imai [10] for Quaternary and Pleistocene deposits of clayey soils (Equations 1 and 2) and Silty/ Sandy soils (Equations 3 and 4), respectively. The data also include the borehole made after earthquake (MSK1, MSK2 and MSK3) [11].

$$
\begin{aligned}
V s & =102 N^{0.292} . \\
V s & =114 N^{0.294} . \\
V s & =80.6 N^{0.331} . \\
V s & =97.2 N^{0.323} .
\end{aligned}
$$

In order to evaluate the consistency of shear wave velocity (Vs) data obtained from a few of the in-situ microtremor tests, average Vs for the top $5 \mathrm{~m}, 10 \mathrm{~m}, 15 \mathrm{~m}, 20 \mathrm{~m}, 25 \mathrm{~m}$ and $30 \mathrm{~m}$ soil layer was calculated at each borehole points by using Equation (5) shown below. Some 
Table 1: Average shear wave velocity from the ground surface to various depths.

\begin{tabular}{llllll}
\hline & Borehole & \multicolumn{3}{l}{ Average Velocity, from ground to } & \\
\cline { 3 - 6 } BH Name & Depth, $\mathrm{m}$ & $10 \mathrm{~m}$ & $15 \mathrm{~m}$ & $20 \mathrm{~m}$ & $25 \mathrm{~m}$ \\
\hline BED148709 & 10.5 & 186 & & & \\
BED148710 & 10.5 & 176 & & & \\
BED155740 & 10.0 & 172 & & & \\
BED155739 & 10.0 & 227 & & 233 & 238 \\
BED155557 & 10.0 & 125 & & 165 & 178 \\
BED155736 & 29.0 & 216 & 227 & 163 & 170 \\
BED151857 & 25.0 & 153 & 156 & 188 & 203 \\
BED155714 & 31.0 & 150 & 160 & 188 & 196 \\
BED155738 & 35.0 & 155 & 165 & 146 & 154 \\
BED155737 & 37.0 & 210 & 198 & 151 & 159 \\
BED155716 & 39.0 & 168 & 186 & 179 \\
BED155713 & 39.0 & 143 & 151 & 137 & 156 \\
BED155715 & 40.0 & 142 & 143 & 172 & 190 \\
MSK1 & 51.5 & 109 & 134 & 115 & \\
MSK2 & 71.0 & 92 & 121 & 147 & \\
MSK3 & 51.5 & & &
\end{tabular}

assumptions were needed at some locations where the SPT value for the surface layer was missing. The calculated average velocity data are shown in Table 1 . These data points are shown as circles in Fig. 7.

$$
V s=\frac{\sum h_{i}}{\sum\left(h_{i} / V s_{i}\right)}
$$

To make an easier comparison, the colour schemes of Vs calculated from boreholes and from phase velocity are made similar. There is a sufficient match between the two and therefore, it assures the reliability of the velocity distribution map prepared.

\section{DISCUSSIONS}

Figure 8 shows the extracts of SPT $\mathrm{N}$ value and Vs values obtained from references. Except somewhat higher Vs at location D, the top 10-m soil layer of all other stations, which primarily affects the bearing and shaking behaviour of the widely distributed oneor two-storied buildings of the area, has very low SPT N value or Vs magnitude. Similar trend could be observed from the calculated profiles, such as in Fig. 7a therefore, the consistency in Vs calculation and the interpolation methods applied in this research can be assured.

The scale of building damage in Mashiki area was quite high [12] and are found to be consistent to some extent with the weaker Vs locations for the top 10-m soil layer (see Fig. 7a and 9). Peak frequency associated with the natural period of soil of such weak areas can be 

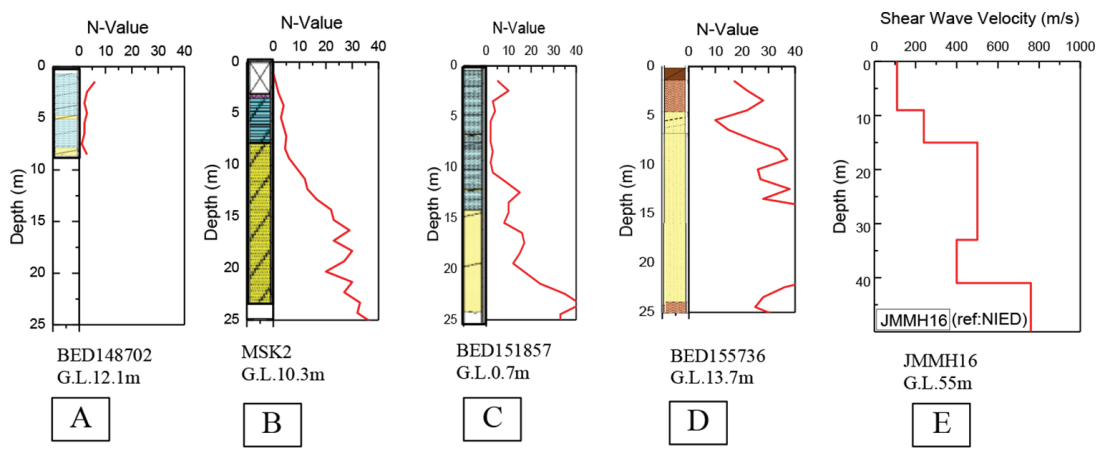

Figure 8: Borehole logs showing SPT values at locations A, B, C [9], D [11]; and Shear wave velocity profile at location E in Fig. 2 [8].

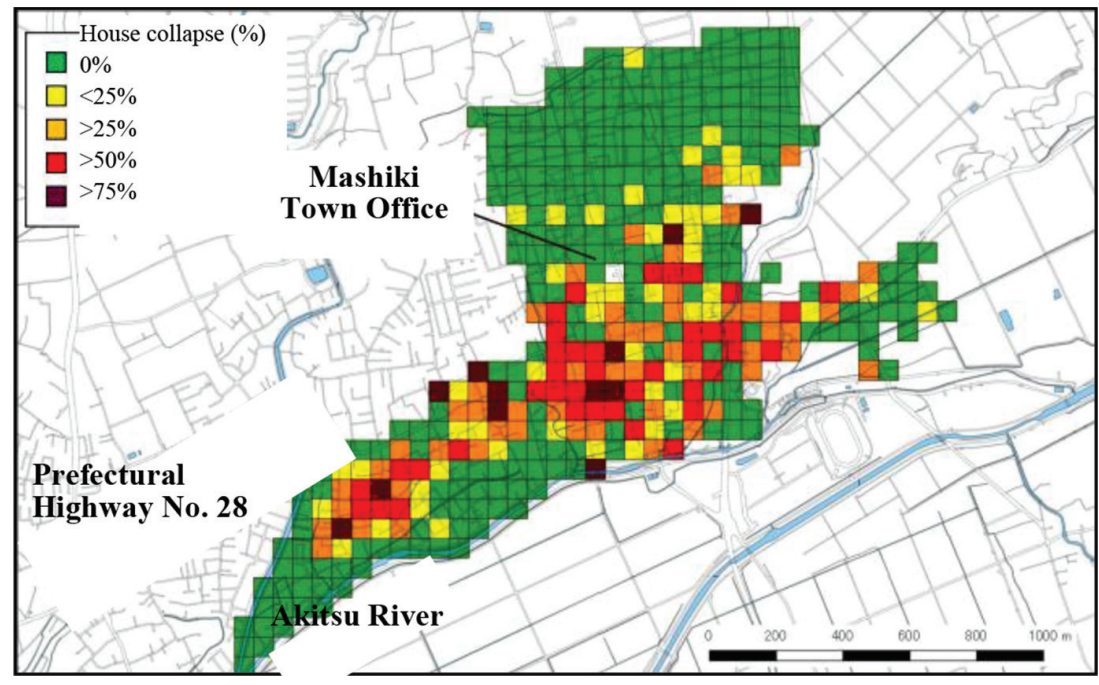

Figure 9: Building collapse situation after Kumamoto earthquake in Mashiki area (reproduced from the map on MLIT report [12]).

read from Fig. 5 as less than 1.0 second therefore, resulted one- or two-storied wooden structures of the area more vulnerable. In the vicinity of JA9 station, which is located in between $\mathrm{B}$ and $\mathrm{C}$ points (Fig. 2), the damage was the most and could be inferred from the very long natural period from in Fig. 4. However, although having lower Vs and longer natural period, the damage along the westward site of Mashiki Town along Akitsu river seems to be relatively small and the reason for such anomaly is not so clear. As the area had both newer and older buildings, the smaller scale of damage may not just be linked with the construction code followed or the year of construction. Thus, these sites need more detailed studies of underlying soil layers and building types to understand the reason of such anomaly. The general trend of higher damage at the sites where calculated velocity was small and had longer natural period to get the insight. 


\section{FINAL REMARKS}

Shear wave velocity distribution of Mashiki Town area was obtained from this study. The Vs from spectral analysis was found to correlate well with the available borehole records. When compared with the extent of building damage, sites with calculated longer natural periods had felt more damage in the field. The accuracy of absolute Vs value and the distribution map, however, needs to be improved with more array measurements and also finding more borehole records in the field.

\section{ACKNOWLEDGEMENT}

Authors are thankful to Dr. M. Yoshimi from AIST, Japan for providing the digital data of three boring locations.

\section{REFERENCES}

[1] MLIT, Report on safety measures for reconstruction of urban areas in Mashiki Town from the Kumamoto earthquake, Ministry of Land, Infrastructure and Transport (MLIT) interim report on December, 2016, available at: (in Japanese) http://www.mlit.go.jp/ report/press/toshi08_hh_000032.html. (accessed 24 April, 2017).

[2] Nagao, T., Lohani, T.N., Fukushima, Y., Ito, Y., Hokugo, A. \& Oshige, J., A study on the correlation between ground vibration characteristic and damage level of structures at Mashiki town by the 2016 Kumamoto earthquake, 2016. (Submitted to Journal of JSCE).

[3] Kudo, K., Sawada, Y. \& Horike, M., Current studies in Japan on H/V and phase velocity dispersion of microtremors for site characterization. 13th World Conference on Earthquake Engineering, 1144, August, 2004.

[4] Aki, K., Space and time spectra of stationary stochastic waves, with special reference to microtremors. Bulletin of Earthquake Research Institute (University of Tokyo), 35, pp. 415-456, 1957.

[5] Haskell, N.A., The dispersion of surface waves on multilayered media. Bulletin of Seismological Society of America, 43(1), pp. 17-34, 1953.

[6] Nagao, T. \& Konno, K., Estimation of average S-wave velocity of ground by use of microtremor array observation. Journal of JSCE, 696, pp. 225-235 (in Japanese), 2002. https://doi.org/10.2208/jscej.2002.696_225

[7] Aoi, S., Obara, K., Hori, S., Kasahara, K. \& Okada, Y., New strong-motion observation network: KiK-net. Eos Transactions American Geophysical Union, 81, 329, 2000.

[8] KMMH16 Borehole data, available at: http://www.kyoshin.bosai.go.jp/cgi-bin/kyoshin/ db/siteimage.cgi?0+/KMMH16+kik+pdf/. (accessed 24 April, 2017).

[9] Kumamoto Earthquake Reconstruction Support borehole map. available at: http:// geonews.zenchiren.or.jp/2016KumamotoEQ/webgis/index.html. (accessed 24 April, 2017).

[10] Imai, T., P and S wave velocities of the ground in Japan. Proceedings of the IXth ICSMFE, 2, pp. 257-260, 1977.

[11] Yoshimi, M., Hata, Y., Goto, H., Hosoya, T., Morita, S. \& Tokumaru, T., Borehole exploration in heavily damaged area of the 2016 Kumamoto earthquake, Mashiki town, Kumamoto. Fall 2016 academic conference, Japan Active Fault Society, October, 2016.

[12] Report to analyze the causes of building damage in the Kumamoto earthquake. MLIT Building Construction Standards Committee, September 2016, available at: http:// www.nilim.go.jp/lab/hbg/kumamotozisinniinnkai/20160912shiryou.htm. (accessed 24 April, 2017). 